\title{
The oncolytic herpes simplex virus vector G47 $\Delta$ effectively targets breast cancer stem cells
}

\author{
WEIGEN ZENG ${ }^{1}$, PAN HU ${ }^{1}$, JUEKUN WU $^{1}$, JIANI WANG $^{1}$, JUNJIE LI $^{2}$, LAN LEI $^{1}$ and RENBIN LIU ${ }^{1}$ \\ ${ }^{1}$ Breast Cancer Center, The Third Affiliated Hospital of Sun Yat-sen University, Guangzhou, Guangdong 510630; \\ ${ }^{2}$ Department of Breast Surgery, The Sichuan Province Cancer Hospital, Chengdu, Sichuan 610041, P.R. China
}

Received October 9, 2012; Accepted November 12, 2012

DOI: $10.3892 /$ or.2012.2211

\begin{abstract}
Accumulating evidence suggests that breast cancer originates from cancer stem cells (CSCs), which comprise a small percentage of the overall tumor but are highly tumorigenic and pluripotent with unlimited proliferation potential. Furthermore, CSCs are highly resistant to conventional treatment, which may explain certain difficulties in treating cancer with current therapy options. In this study, the third generation oncolytic herpes simplex virus (oHSV) vector G47 $\Delta$ effectively killed different subtypes of breast cancer cells, with more than $98 \%$ of the tumor cells killed by Day 5 . Moreover, G47 $\Delta$ targeted equally non-cancer stem cells (NCSCs) and CSCs which showed resistance to paclitaxel. We demonstrated that

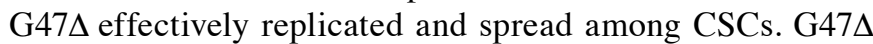
also impaired the self-renewal ability of CSCs, as the viable cells were unable to form secondary tumor spheres. We also showed that G47 $\Delta$ was able to induce the regression of tumor xenografts in BALB/c nude mice and demonstrated the ability of G47D to synergize with paclitaxel by killing both NCSCs and CSCs, suggesting that oHSV may be an effective treatment modality for patients with breast cancer.
\end{abstract}

\section{Introduction}

The cancer stem cell (CSC) theory proposes that tumor cells are composed of a heterotypic population of cells and the CSCs, which comprise a small percentage of the total tumor, remain at the top of the cellular hierarchy with unlimited proliferation potential and pluripotency $(1,2)$. Recent evidence indicates that breast CSCs are relatively resistant to both radiation and chemotherapy $(3,4)$. Therefore, new treatment strategies that effectively target both NCSCs and CSCs show promise as an effective treatment for breast cancer.

Correspondence to: Professor Renbin Liu, Breast Cancer Center, The Third Affiliated Hospital of Sun Yat-sen University, 600 Tianhe Road, Guangzhou, Guangdong 510630, P.R. China

E-mail: liur@vip.163.com

Key words: breast cancer, cancer stem cell, oncolytic virus, herpes simplex virus self-renewal, triple-negative breast cancer
The oncolytic herpes simplex virus (oHSV) vector has been shown to be a safe and effective therapeutic approach for various types of cancer, including breast cancer $(5,6)$. G47 $\Delta$ is a third-generation replication-competent HSV-1 vector based on G207 by deletion of the ICP47 gene (7). The deletion of ICP47 not only upregulates the expression of MHC class I on the surface of G47 $\Delta$-infected cells, but also deletes the US11 promoter which makes the late US11 gene under the control of immediate early ICP47 promoter, thereby enhancing growth of G47 $\Delta$ by precluding shutoff of protein synthesis. This makes G47 $\Delta$ more effective than G207 in killing tumor cells. We previously reported that $\mathrm{G} 47 \Delta$ effectively targeted breast cancer both in vitro and in vivo $(5,6)$.

In the present study, we showed that G47 $\Delta$ effectively killed different types of breast cancer cells in vitro. We found that G47 $\Delta$ also effectively targeted CSCs in vitro and impaired their self-renewal ability. Finally, we demonstrated that G47 $\Delta$ could induce the regression of tumor xenografts in BALB/c mice and worked synergistically with paclitaxel in killing both NCSCs and CSCs.

\section{Materials and methods}

Cells and viruses. Breast cancer cell lines MCF-7, SK-BR-3, MDA-MB-435, MDA-MB-436 and MDA-MB-468 were obtained from Dr Xie Xiao-ming (Sun Yat-sen University Cancer Center, China). G47 $\Delta$ was constructed as previously described (7) and was obtained from Dr Samuel D. Rabkin, Molecular Neurosurgery Laboratory, Massachusetts General Hospital, Harvard Medical School, Boston, MA, USA). Viruses were grown and titered using Vero cells (African green monkey kidney cells; ATCC, Manassas, VA, USA).

In vitro cytotoxicity of the parental cell lines. Cells were infected with mock or viruses at multiplicity of infection (MOI) of 0.1 and 0.01, then incubated in Dulbecco's modified Eagle's medium (DMEM; Invitrogen, USA) supplemented with $1 \%$ heat-inactivated fetal calf serum. Cells were stained with trypan blue (Sigma, USA) and counted on a hemocytometer.

For combination therapy, cells were seeded into a $10-\mathrm{cm}$ culture dish and infected with viruses at a MOI of $0.5,1 \mathrm{nM}$ paclitaxel (Sigma), G47 $\Delta+$ paclitaxel or a mock treatment. Cells were incubated at $37^{\circ} \mathrm{C}$ for 4 days in DMEM supplemented with $10 \%$ heat-inactivated fetal calf serum. Cells were harvested and 

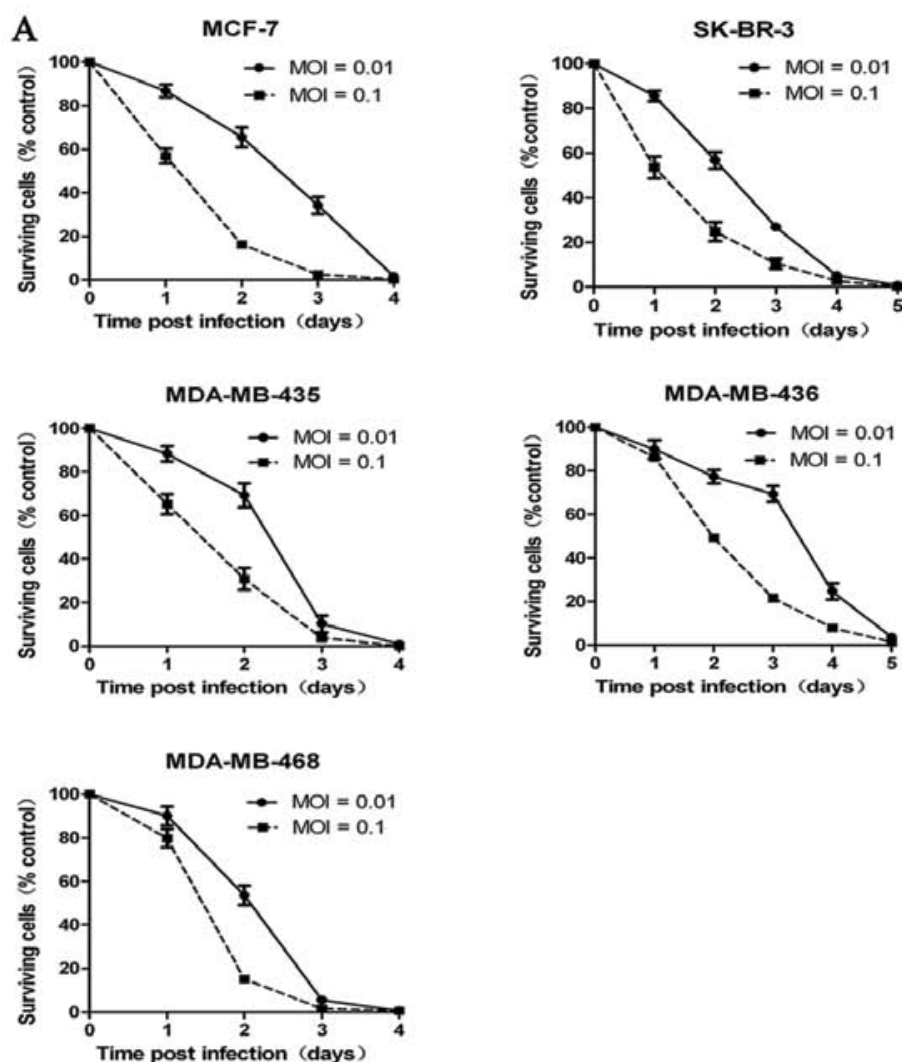

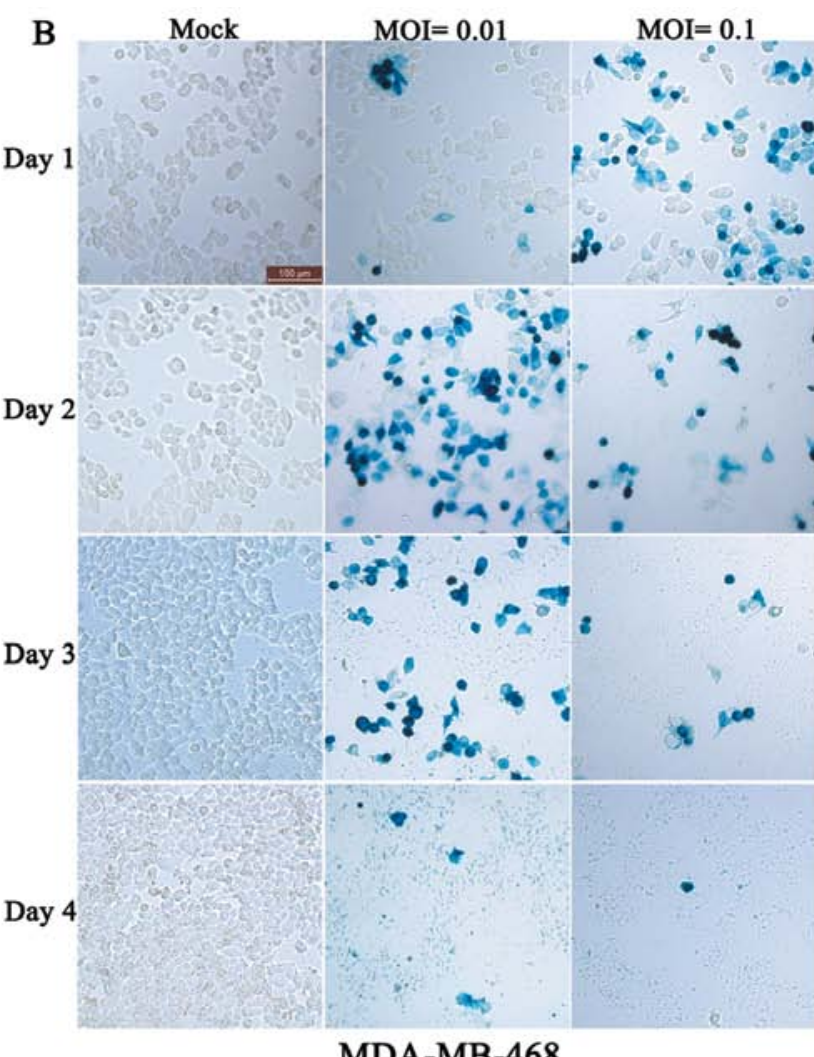

MDA-MB-468

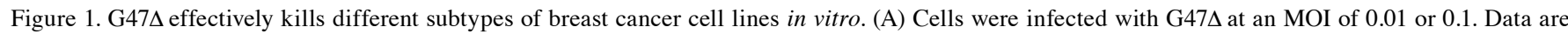
presented as mean values $\pm \mathrm{SD}(\mathrm{n}=3)$. The data are representative of three independent trials. (B) MDA-MB-468 cells were stained with X-gal. Scale bar, $100 \mu \mathrm{m}$.

counted on Day 4 and stained with fluorescein isothiocyanatelabeled (FITC) anti-CD44 and phycoerythrin-labeled (PE) anti-CD24 antibodies (both from Beckman Coulter, Brea, CA, USA). The stained cells were assayed by flow cytometry (Becton-Dickinson), and the percent of CD $44^{+} \mathrm{CD} 24^{-}$cells was calculated.

Isolation and identification of CSCs. As previously described (8), cells were cultured in DMEM/F12 medium supplemented with $10 \mu \mathrm{g} / 1$ basic fibroblast growth factor, $20 \mu \mathrm{g} / 1$ epidermal growth factor, $5 \mathrm{mg} / 1$ insulin and B27 (all from Invitrogen). Cells generally formed mammospheres within 10 days.

The mammospheres and parental cell lines were trypsinized and stained with anti-CD44 and anti-CD24 antibodies as described above. The Aldefluor assay was performed according to the manufacturer's protocol (Stemcell Technologies, Canada).

In vitro cytotoxicity of $G 47 \Delta$ on CSCs. Mammospheres were dissociated, the resulting single cells were resuspended at $1 \times 10^{7}$ cells $/ \mathrm{ml}$ and infected at an MOI of 0.1 or mock-infected for $90 \mathrm{~min}$ at $37^{\circ} \mathrm{C}$. The cells were then centrifuged to remove unadsorbed viruses and seeded in 6 -well plates at $1 \times 10^{5}$ cells per well. Cells were counted on Days 3 and 7 using a hemocytometer.

Cells were harvested along with the associated supernatant at 12,36 and $60 \mathrm{~h}$ post-infection. After three freeze/thaw cycles, the titers of infectious virus were tested using a plaque assay with Vero cells.
Seven days following virus infection, the viable cells were collected, resuspended in fresh medium, and seeded into 96-well plates at a density of 1 or 10 cells per well. Two weeks later, the number of wells containing mammospheres (diameter $>40 \mu \mathrm{m}$ ) was recorded.

In vivo treatment studies. MDA-MB-468 mammosphere cells $\left(1 \times 10^{6}\right)$ were implanted into the left flank of 6-week-old female BALB/c nude mice (Vital River Laboratory Animal Technology Co., Ltd., China). When tumors reached a maximal diameter of $\sim 5 \mathrm{~mm}$, mice were randomized into 4 groups of 7 mice per group. The groups consisted of a G47D treatment group that was given a 50- $\mu$ l intratumor (i.t.) injection of G47 $\Delta$ virus $\left(2 \times 10^{7}\right.$ plaque-forming units, pfu) on Days 0 and 3 , a paclitaxel treatment group treated with an intraperitoneal (i.p.) injection of $3 \mathrm{mg} / \mathrm{kg}$ paclitaxel on Days 0 and 7, a combination treatment group that was treated with G47 $\Delta$ and paclitaxel on the same dosing schedule, and a mock treatment group. Tumor volume was calculated using the formula: width $(\mathrm{mm})^{2}$ $\mathrm{x}$ length $(\mathrm{mm}) \mathrm{x} 0.5$.

Tumor tissue was minced and digested for $\sim 6 \mathrm{~h}$ at $37^{\circ} \mathrm{C}$ using a solution of $100 \mathrm{U} / \mathrm{ml}$ collagenase I, $150 \mathrm{U} / \mathrm{ml}$ hyaluronidase, $10 \%$ calf serum, and $5 \mathrm{mg} / \mathrm{l}$ bovine insulin in DMEM (all from Invitrogen). Digested tissue was strained using a $40-\mu \mathrm{m}$ strainer, the cell suspension was washed with PBS and the red blood cells were lysed for $5 \mathrm{~min}$ (Bomeike Biotechnology, China). The samples were analyzed for the percentage of $\mathrm{CD} 44^{+} \mathrm{CD} 24^{-}$cells using flow cytometry. All 

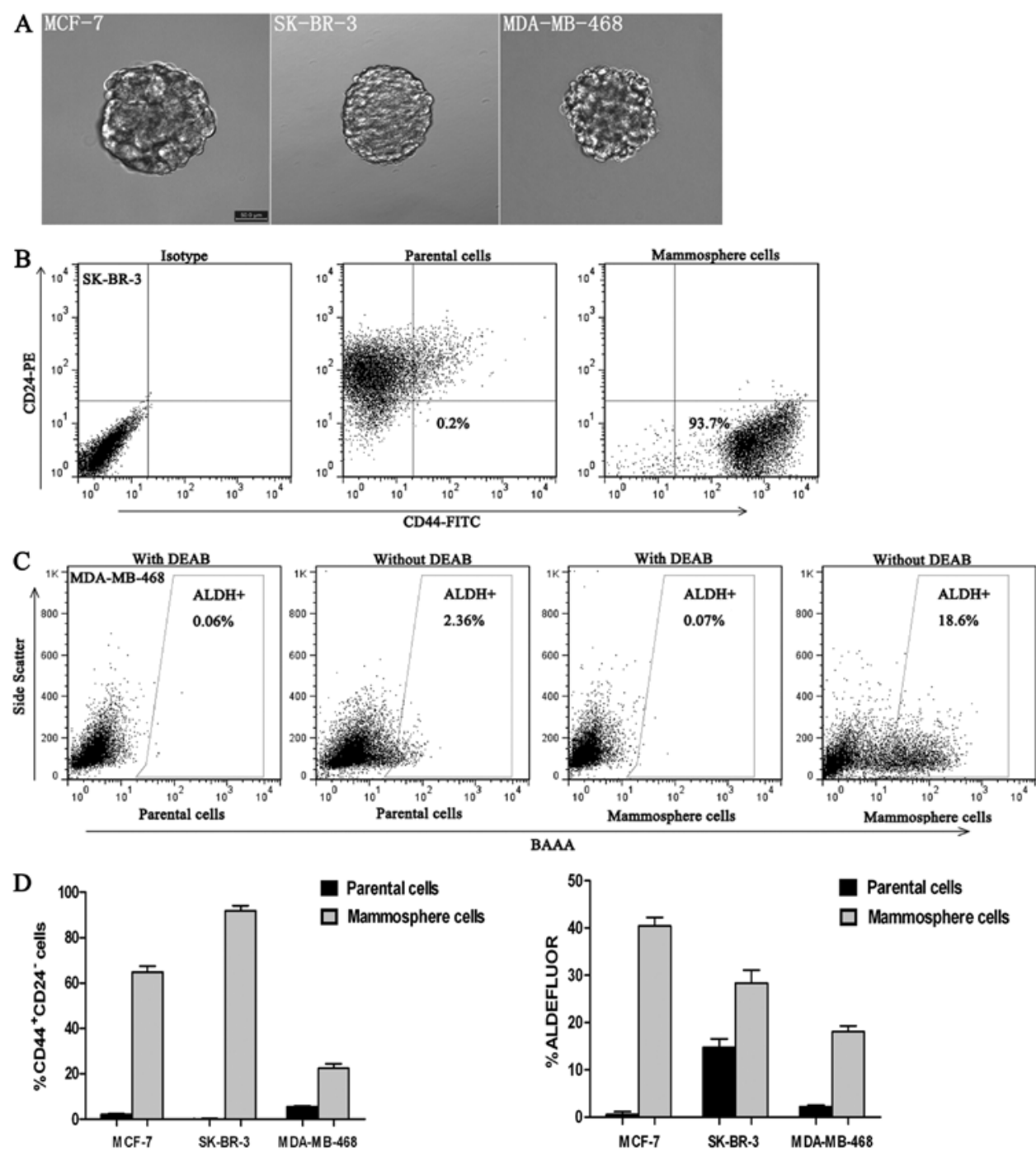

Figure 2. Isolation and identification of breast cancer stem cells. (A) Microscopic image of mammosphere in adherent culture. Scale bar, $50 \mu \mathrm{m}$. (B) The percentage of $\mathrm{CD}_{4} 4^{+} \mathrm{CD} 24{ }^{-}$cells of parental SK-BR-3 cells and mammosphere cells was $0.23 \pm 0.08$ and $91.69 \pm 2.27 \%$ (P<0.001), respectively. (C) ALDH ${ }^{+}$ cells comprised $2.31 \pm 0.27 \%$ of the MDA-MB-468 parental cell line, whereas $\mathrm{ALDH}^{+}$cells comprised $18.14 \pm 1.21 \%$ of mammosphere cells (P<0.001). (D) The percentages of $\mathrm{CD} 44^{+} \mathrm{CD} 24^{-}$cells and ALDH-1 positive cells in mammospheres were higher relative to the parental cell lines in all breast cancer cell lines. Bars, \pm SD. The data are representative of three independent trials.

animal procedures were approved by the Animal Care and Use Committee of Sun Yat-sen University.

$X$-gal histochemistry. X-gal staining was performed according to the manufacturer's protocol (Beyotime Institute of Biotechnology, China).

Statistical analysis. Data are presented as the means \pm standard deviation (SD). Each experiment was repeated in at least three independent trials. A Student's t-test was used to analyze the significance of differences between two treatment groups. SPSS version 13.0 software was used, and $\mathrm{P}<0.05$ was considered to indicate a statistically significant difference.

\section{Results}

G47A effectively kills different types of breast cancer cell lines in vitro. Neve et al (9) reported that breast cancer cell lines effectively model primary breast tumors. MCF-7, SK-BR-3 and three other cell lines represent luminal subtype tumors, HER-2 overexpression subtype and basal-like subtype, respectively. We showed that G47 4 effectively killed different subtypes of tumors (Fig. 1A). MCF-7, MDA-MB-435 and MDA-MB-468 were highly sensitive to G47 $\Delta$-mediated killing with $>98 \%$ of these tumor cells dying by Day 4 with an MOI of 0.01 . By Day 3, almost all the MDA-MB-468 cells were infected by G47 (Fig. 1B). SK-BR-3 and MDA-MB-436 cells displayed a moderate sensitivity to G47 $\Delta$-mediated killing with $>98 \%$ of cells dying by Day 5 . These findings demonstrate that G47 $\Delta$ can effectively kill different subtypes of breast cancer cells.

Isolation and identification of CSCs. CSCs typically form mammospheres within 10 days of anchorage-independent culture. Our mammosphere cultures could be passaged for $>3$ months. Moreover, single dissociated mammosphere cells were able to regenerate spheres, thereby indicating their clonogenicity (Fig. 2A and Table I). Using the cultured CSCs, we investigated the percentage of mammosphere cells 
Table I. CSCs that survive infection with G47 $\Delta$ are unable to form secondary mammospheres.

\begin{tabular}{|c|c|c|c|}
\hline Cell & MOI & $\begin{array}{l}\text { Cell no. } \\
\text { per well }\end{array}$ & $\begin{array}{l}\text { No. of wells with } \\
\text { spheres/96-wells }\end{array}$ \\
\hline
\end{tabular}

\begin{tabular}{llrr}
\hline MCF-7 & 0 & 10 & 70 \\
& 0 & 1 & 13 \\
SK-BR-3 & 0.1 & 10 & 0 \\
& 0 & 10 & 88 \\
& 0 & 1 & 21 \\
MDA-MB-468 & 0.1 & 10 & 0 \\
& 0 & 10 & 58 \\
& 0.1 & 10 & 10 \\
\hline
\end{tabular}

After 7 days of infection with $\mathrm{G} 47 \Delta$, a minor population of cells remained viable. Viable cells were seeded into 96-well plates at a density of 1 or 10 cells per well, and the number of wells containing mammospheres was counted after 14 days. The data show the mean values of three separate experiments. CSCs, cancer stem cells; MOI, multiplicity of infection.

that displayed the stem cell-like phenotype $\mathrm{CD} 44^{+} \mathrm{CD} 24^{-}$and aldehyde dehydrogenase (ALDH. In contrast to their respective parental cell lines, cells derived from mammosphere cells were enriched for $\mathrm{CD} 44^{+} \mathrm{CD} 24^{-}$and $\mathrm{ALDH}^{+}$cells. CD $44^{+} \mathrm{CD} 24^{-}$cells accounted for $0.23 \pm 0.08 \%$ of parental SK-BR-3 cells, whereas CD $44^{+} \mathrm{CD} 24^{-}$cells accounted for $91.69 \pm 2.27 \%$ of mammosphere cells derived from the SK-BR-3 cell line (Fig. 2B). The percentage of $\mathrm{ALDH}^{+}$cells in the MDA-MB-468 parental cell line was $2.31 \pm 0.27 \%$, whereas $\mathrm{ALDH}^{+}$cells accounted for $18.14 \pm 1.21 \%$ of mammosphere cells derived from the MDA-MB-468 cell line $(\mathrm{P}<0.001)$ (Fig. 2C). Mammosphere cells from the other breast cancer cell lines displayed a similar enrichment for $\mathrm{CD}_{4} 4^{+} \mathrm{CD} 24^{-}$or $\mathrm{ALDH}^{+}$cells relative to their respective parental cell line (Fig. 2D).
These results show that anchorage-independent cell culture results in the production of mammosphere cells that are enriched with cells expressing breast CSC markers, and these cells display undifferentiated stem-like characteristics.

G474 effectively targets breast CSCs in vitro. CSCs were cultured under anchorage-independent conditions and infected with $\mathrm{G} 47 \Delta$ at a MOI of 0.1 . Our results showed that CSCs were sensitive to G47D (Fig. 3A). Similar to the parental cell lines, MCF-7, SK-BR-3 and MDA-MB-468 grown under anchorageindependent conditions were also effectively killed by G47 $\Delta$ with $>98 \%$ of CSCs killed by Day 7 . To determine whether G47D could replicate and spread among CSCs, we quantified viral replication using the plaque-forming unit (PFU) assay. The CSCs and their associated supernatants were collected at indicated time points after infection, and virus titers were determined after three freeze/thaw cycles by the PFU assay using Vero cells. We found that $\mathrm{G} 47 \Delta$ replicated considerably in MCF-7, SK-BR-3 and MDA-MB-468 cells (Fig. 3B). Collectively, these results demonstrate that G47D effectively targets breast CSCs.

G47A kills breast NCSCs and CSCs equally and synergizes with paclitaxel by killing both NCSCs and CSCs in vitro. A previous study demonstrated that CSCs are relatively resistant to chemotherapy (4). This study showed that treatment with the standard breast cancer drug paclitaxel resulted in an increase in the proportion of $\mathrm{CD} 44^{+} \mathrm{CD} 24^{-}$cells (4). Therefore, we determined whether NCSCs were more sensitive to G47 $\Delta$ than CSCs. To this end, we tested the proportion of CD44 ${ }^{+} \mathrm{CD} 24$ cells before and after treatment with G47 $\Delta$ or paclitaxel. Similar to previous research, our results showed that CSCs were generally resistant to paclitaxel-mediated cell death, and, following treatment with paclitaxel, the proportion of $\mathrm{CD} 44^{+} \mathrm{CD} 24^{-}$cells increased $(13.13 \pm 0.43 \%)$ when compared with the control group $(5.41 \pm 0.42 \%, \mathrm{P}<0.001)$ (Fig. 4). By contrast, the proportion of $\mathrm{CD} 44^{+} \mathrm{CD} 24^{-}$cells did not change relative to the control cells after treatment with $\mathrm{G} 47 \Delta(5.44 \pm 0.39 \%, \mathrm{P}>0.05)$. Moreover, when G47 $\Delta$ was used in combination with pacli-
A

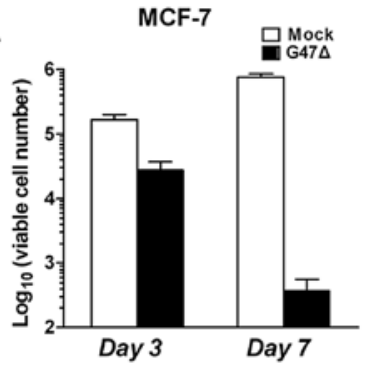

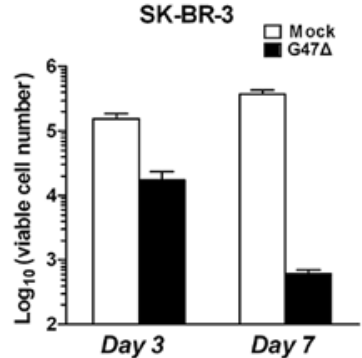

Day 7

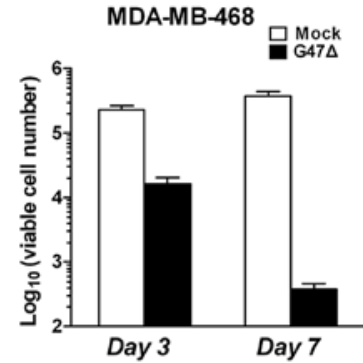

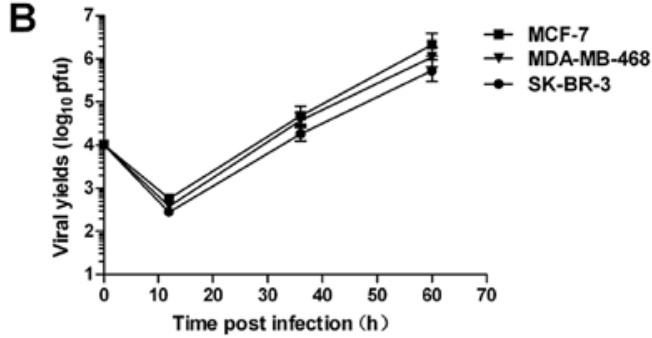

Figure 3. G47D effectively targets breast CSCs in vitro. (A) CSCs were infected with G47 $\Delta$ at an MOI of 0.1 under anchorage-independent culture conditions, and the cells were counted on Days 3 and 7. More than $98 \%$ of the cells were killed by Day 7. (B) The titers of infectious virus were determined using the plaque assay with Vero cells as the host. Bars, \pm SD. The data are representative of three independent trials. 


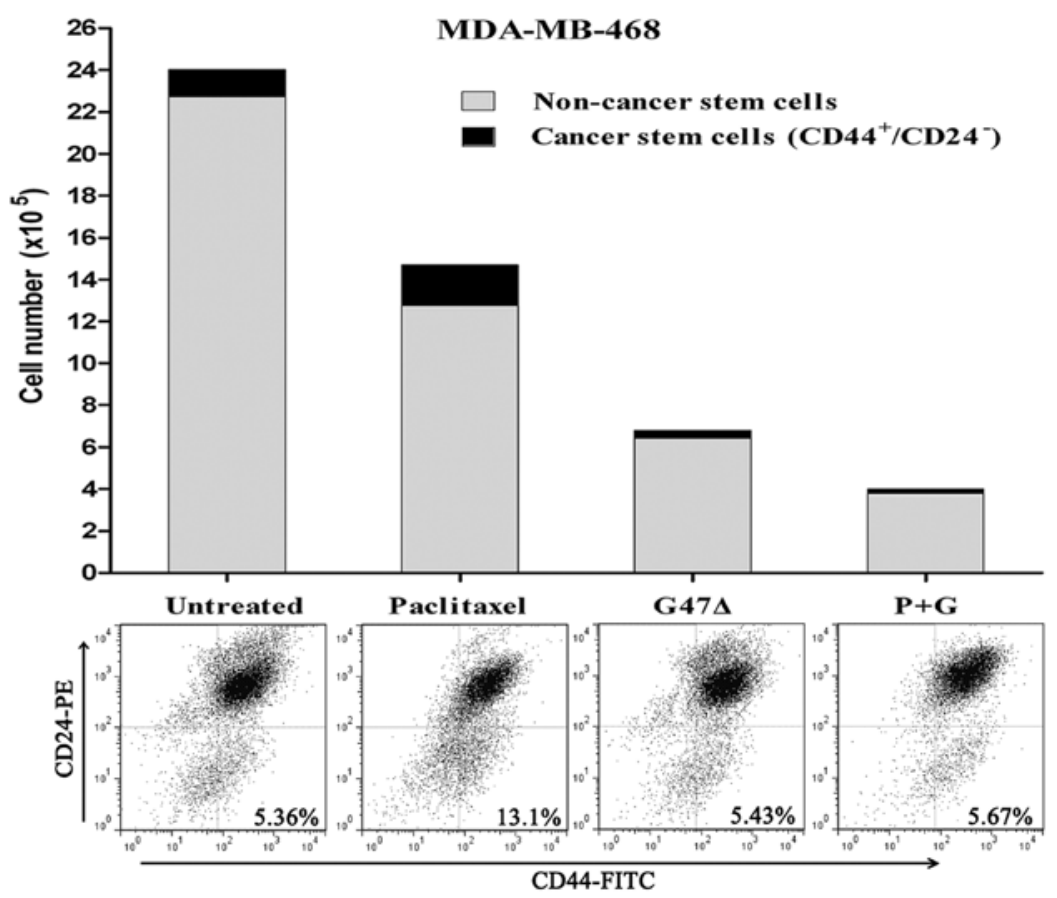

Figure 4. G47 4 equally targets breast NCSCs and CSCs and synergizes with paclitaxel by killing both NCSCs and CSCs in vitro. After infecting breast cancer cells with $\mathrm{G} 47 \Delta$, the proportion $\mathrm{CD} 44^{+} \mathrm{CD} 24$ cells $(5.44 \pm 0.39 \%)$ remained unchanged when compared with the control group $(5.41 \pm 0.42 \%, \mathrm{P}>0.05)$ on Day 4 . However, the CSCs did not appear sensitive to paclitaxel as paclitaxel treatment resulted in a 1.43 -fold increase in the proportion of $\mathrm{CD} 44^{+} \mathrm{CD} 24^{-}$cells $(13.13 \pm 0.43 \%, \mathrm{P}<0.001)$ Moreover, when G47 $\Delta$ was administered in combination with paclitaxel, this treatment showed a synergistic effect by killing both NCSCs and CSCs but did not result in an increase in the proportion of stem cells $(5.55 \pm 0.32 \%, P>0.05)$. Data are presented as mean values $\pm S D(n=3)$. The data are representative of three independent trials. Statistical significance was determined using Student's t-test.
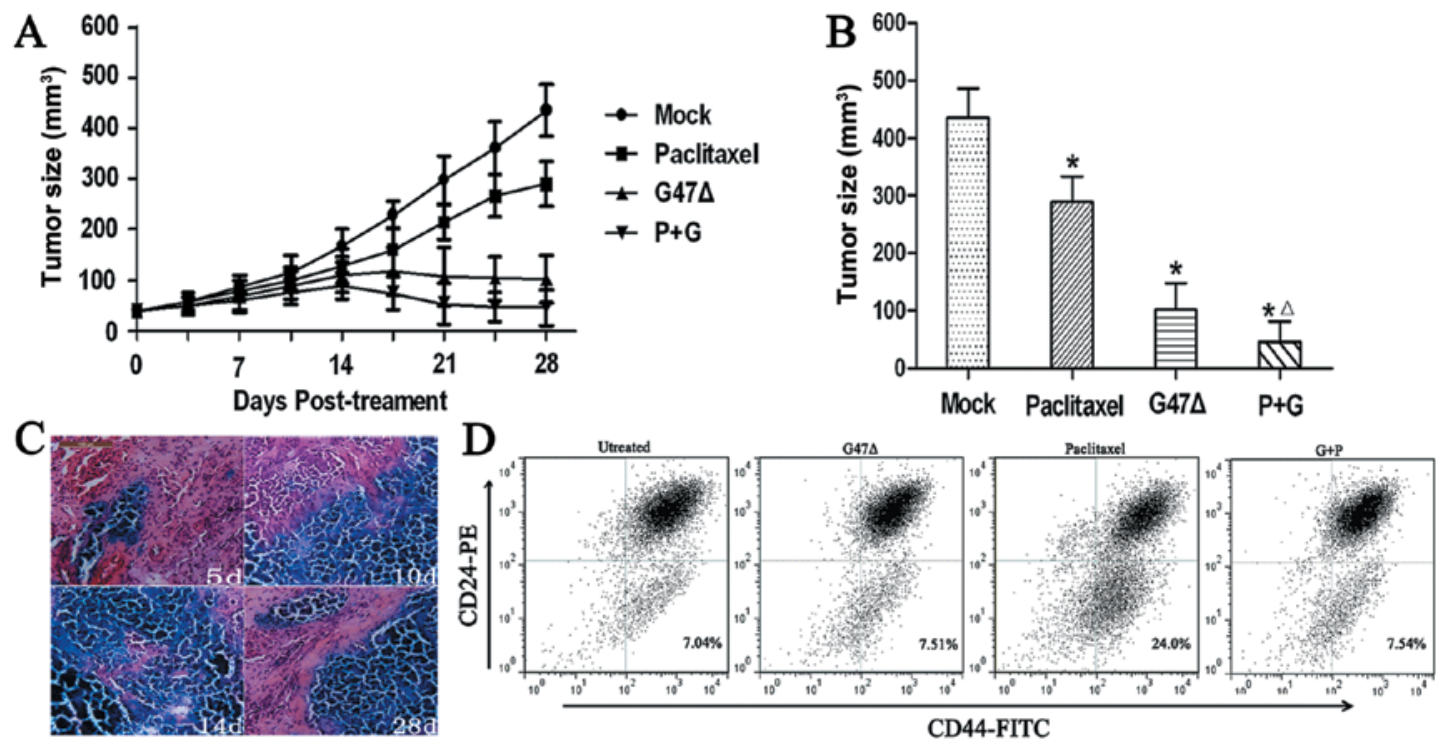

Figure 5. G47 $\Delta$ induces regression of tumors xenografted to BALB/c mice. (A and B) G47 4 effectively killed tumor cells in vivo, and the combination group showed the greatest extent of tumor regression $\left(45.9 \pm 35.4 \mathrm{~mm}^{3}\right)$ on Day 28 relative to the control treatment group $\left(435.3 \pm 50.25 \mathrm{~mm}^{3}\right)$, the G47 treatment group $\left(101.6 \pm 46.7 \mathrm{~mm}^{3}\right)$ or the paclitaxel treatment group $\left(288.9 \pm 44.4 \mathrm{~mm}^{3}\right)$. G47 $\Delta$ efficiently replicated and spread to other tumor cells in vivo, and the most extensive X-gal staining was apparent at 14 days post-inoculation (C). By Day $28, \mathrm{G} 47 \Delta$ retained the ability to replicate in vivo. Similar to the in vitro experiments, the proportion of $\mathrm{CD} 44^{+} \mathrm{CD} 24$ cells did not increase after treatment with $\mathrm{G} 47 \Delta(7.48 \pm 0.37 \%)$ when compared with the control group $(7.23 \pm 0.45 \%$, $\mathrm{P}>0.05)$. However, the proportion of the $\mathrm{CD} 44^{+} \mathrm{CD} 24$ - cells increased by 2.27 -fold after treatment with paclitaxel $(23.6 \pm 2.54 \%)(\mathrm{P}<0.001)$. We found that $\mathrm{G} 47 \Delta$ and paclitaxel showed a synergistic effect by killing both NCSCs and CSCs in vivo. The proportion of CD44 ${ }^{+} \mathrm{CD} 24$ cells in the combination treatment group was $7.51 \pm 0.63 \%(P>0.05)$. Bars, \pm SD. Data are presented as mean values $\pm S D(n=7)$. Statistical significance was determined using Student's $t$-test. Scale bar, $100 \mu \mathrm{m}(\mathrm{C}) .{ }^{*} \mathrm{P}<0.001$ relative to the control group. ${ }^{\triangle} \mathrm{P}<0.05$ relative to the $\mathrm{G} 47 \Delta$ single-treatment group.

taxel, we observed a synergistic effect resulting in the death of both NCSCs and CSCs, the percentage of stem cells remained unchanged $(5.55 \pm 0.32 \%, \mathrm{P}>0.05)$. Collectively, these results demonstrate that $\mathrm{G} 47 \Delta$ is equally effective in killing both breast NCSCs and CSCs. Furthermore, G47 4 can synergize with paclitaxel to kill both NCSCs and CSCs in vitro. 
The self-renewal of CSCs is impaired after G47A infection. Self-renewal is one of the defining properties of CSCs, and the ability to form spheres in vitro is considered an indicator

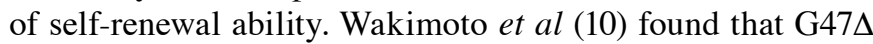
infection impairs the self-renewal ability of glioblastoma stem cells. Therefore, we used single-cell-derived mammosphere cells to determine whether G47 $\Delta$ could impair the self-renewal ability of breast CSCs. Although G47 $\Delta$ killed almost all mammosphere cells by Day 7, we observed a minor population of cells that remained alive after 7 days of infection with G47D. Live cells were collected and subjected to a limiting dilution assay to determine whether these cells maintained the ability to generate secondary mammospheres. Our results showed that none of the cells that survived following G47 $\Delta$ infection were able to generate secondary mammospheres when seeded at up to 10 cells per well (Table I). By contrast, as few as one live cell from the control treatment group was able to form secondary mammospheres. Collectively, these results suggest that G47 $\Delta$ may inhibit the self-renewal of breast CSCs regardless of whether they undergo oncolysis. However, the underlying mechanism remains to be determined and warrants further investigation.

G474-induced regression of tumor xenografts in $B A L B / c$ mice. We chose MDA-MB-468 mammosphere cells to form tumors in BALB/C mice, as MDA-MB-468 is a basal-like cell line that is very aggressive and forms large tumors that are resistant to tamoxifen or trastuzumab (11). Mice were injected with MDA-MB-468 mammosphere cells, and after flank tumors developed, the mice were divided into four treatment groups. One group was treated with a mock treatment, another group received an i.t. G47 $\Delta$ injection, one group received an i.p. paclitaxel injection, and one group received G47 + paclitaxel. Our results showed that G47 $\Delta$ effectively killed tumor cells in vivo since the mice that received G47 $\Delta$ alone showed a significant reduction in their mean tumor volume $\left(101.6 \pm 46.7 \mathrm{~mm}^{3}\right)$ when compared with the mock treatment group $\left(435.3 \pm 50.25 \mathrm{~mm}^{3}\right)$ by Day $28(\mathrm{P}<0.001)$ (Fig. 5A and B). However, we also observed that the group of mice that received $\mathrm{G} 47 \Delta+$ paclitaxel displayed a synergistic effect in vivo and a significant reduction in the mean tumor volume $\left(45.9 \pm 35.4 \mathrm{~mm}^{3}\right)$ when compared with $\mathrm{G} 47 \Delta$ alone $\left(101.6 \pm 46.7 \mathrm{~mm}^{3}\right)$, paclitaxel alone $\left(288.9 \pm 44.4 \mathrm{~mm}^{3}\right)$, or mock treatment groups $\left(435.3 \pm 50.25 \mathrm{~mm}^{3}\right)$ by Day $28(\mathrm{P}<0.05$ for all three comparisons) (Fig. 5A and B). Furthermore, the combined treatment showed no signs of toxicity as the body weights of the mice were similar among the four groups (mean body weight, $22.3 \mathrm{~g}$ ), and body weight did not significantly change over the course of the study.

We also found that G47 $\Delta$ effectively replicated and spread among tumor cells in vivo, and the most extensive $\mathrm{X}$-gal staining was apparent 14 days post-inoculation (Fig. 5C). By Day 28, we found that $\mathrm{G} 47 \Delta$ remained capable of in vivo replication.

We found that mammosphere cells derived from MDA-MB-468 could differentiate into different types of cancer cells in vivo. The proportion of $\mathrm{CD} 44^{+} \mathrm{CD} 24^{-}$cells of the control treatment group $(7.23 \pm 0.45 \%)$ was similar to the MDA-MB-468 cell line in vitro $(5.35 \pm 0.42 \%)$ (Fig. $5 \mathrm{D})$. G47 4 effectively killed both CSCs and NCSCs in vivo, and the proportion of the $\mathrm{CD} 44^{+} \mathrm{CD} 24$ cells $(7.48 \pm 0.37 \%, \mathrm{P}>0.05$, compared with the control group) did not increase after treatment with G47A, which was similar to the in vitro results. However, the proportion of $\mathrm{CD} 44^{+} \mathrm{CD} 24^{-}$cells $(23.6 \pm 2.54 \%$, $\mathrm{P}<0.001$, compared to the control group) increased 2.27-fold after treatment with paclitaxel. Notably, we found G47 $\Delta$ and paclitaxel showed a synergistic effect by killing both NCSCs and CSCs in vivo. The proportion of $\mathrm{CD} 44^{+} \mathrm{CD} 24^{-}$cells in the combination treatment group was $7.51 \pm 0.63 \%$, which was similar to the control treatment group $(\mathrm{P}>0.05$, compared to the control group).

Collectively, these results suggest that G47 $\Delta$ effectively kills breast NCSCs and CSCs in vivo and has a synergistic effect with paclitaxel by killing both CSCs and NCSCs.

\section{Discussion}

Different breast cancer subtypes categorized based on molecular characteristics have been shown to be highly associated with patient prognosis; these characteristics also serve as predictive tools for the efficacy of a particular therapy in a given patient. Luminal subtype of breast tumors usually have an excellent prognosis and do not benefit significantly from chemotherapy (12). For patients whose tumors highly express the HER-2 gene, trastuzumab significantly improves the disease-free and overall survival $(13,14)$. However, although triple-negative breast cancers (TNBCs) or basal-like tumors tend to be highly sensitive to chemotherapy, they tend to have the worst prognosis and highest recurrence rates (15-17). Moreover, there are no approved drugs that specifically target TNBCs. There is a substantial ongoing effort to develop therapeutics that effectively target all subtypes of breast cancer and TNBC in particular. In this study, we have shown that G47 $\Delta$ effectively kills all types of breast cancer cells regardless of the ER, PR and HER-2 status. G47 $\Delta$ may represent a promising therapeutic agent for the treatment of all subtypes of breast cancer.

Breast CSCs were isolated based on the expression of the two cell surface markers CD44 and CD24 or expression of aldehyde dehydrogenase 1 (ALDH1) $(18,19)$. Previous studies have demonstrated that $\mathrm{CD}_{4} 4^{+} \mathrm{CD} 24^{-}$cells are highly tumorigenic and can give rise to a large and diverse population of tumor cell types (18). Ginestier et al (19) showed $\mathrm{ALDH}^{+}$ cells were highly tumorigenic, and patients with a higher percentage of $\mathrm{ALDH}^{+}$cells had the worst clinical outcomes. Recent studies reveal that stem/progenitor tumor cells can grow in non-adherent conditions based on the unique properties of stem/progenitor cells that allow them to survive and grow in a serum-free suspension culture (8). Thus, the tumorsphere assay allows researchers to culture breast tumor cells with stem/progenitor cell properties for a long period of time, which represents a suitable in vitro model for the study of breast cancer-initiating cells. We used anchorage-independent cell culture conditions to enrich for CSCs and found that mammosphere cells were enriched with cells expressing breast CSC markers, and these cells display undifferentiated stemlike characteristics.

Despite the improvements in treatment regimens, approximately $30 \%$ of patients with an early-stage disease eventually develop recurrent and metastatic lesions (20). CSCs are considered the main source of recurrence and metastasis $(1,2)$. CSCs are relatively resistant to chemotherapy and radiotherapy; 
moreover, breast CSCs appear to be ER negative and may play an important role in resistance to endocrine therapy (21).

oHSV viral vectors selectively replicate within tumors and directly destroy tumor cells by virus-induced cell lysis. This mechanism is distinctly different from routine cancer therapies, such as chemotherapy and endocrine therapy. We

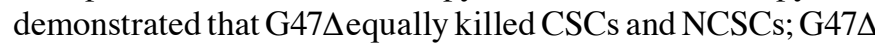
also displayed a synergistic effect with paclitaxel by killing both CSCs and NCSCs, and G47D showed no obvious signs of toxicity in mice. G47 $\Delta$ might be an effective new strategy to target CSCs and to use in conjunction with conventional chemotherapy to achieve the greatest effect. Ahtiainen et al (22) found that breast CSCs had innate immunity defects which rendered breast CSCs permissive to oncolytic adenovirus. Next, we may focus on the immune response of breast CSCs to G47D infection both in vitro and in vivo.

CSCs have the ability of self-renewal, and only CSCs are believed to have the ability to proliferate indefinitely to generate new tumors. Through asymmetric division, CSCs divide to produce one daughter stem cell and one daughter cell that may differentiate into a nontumorigenic cell. This theory suggests that agents that target the self-renewal pathways in CSCs could represent effective routes of therapy. Our results show that CSCs that survive G47D infection are unable to form secondary mammospheres, thereby indicating that the self-renewal ability of CSCs remains impaired by G47 $\Delta$ even if lysis does not occur. Similarly, Wakimoto et al (10) reported that the inhibition of self-renewal by G47 $\Delta$ may be due to factors secreted by $\mathrm{G} 47 \Delta$ or due to $\mathrm{G} 47 \Delta$ directly inhibiting the self-renewal pathways. The mechanism whereby G47 $\Delta$ inhibits the self-renewal capability of stem cells remains unknown and warrants further investigation.

In conclusion, we have shown that G47 $\Delta$ effectively and equally targets NCSCs and CSCs derived from different breast cancer subtypes. Furthermore, G47 $\Delta$ appeared to impair the self-renewal ability of CSCs. G47D also demonstrated a synergistic effect with paclitaxel to amplify the killing of both NCSCs and CSCs in vitro and in vivo. To our knowledge, this is the first report on the targeted treatment of breast CSCs with oHSV.

\section{Acknowledgements}

This study was supported by the National Natural Science Foundation of China (grant no. 30672410) and Natural Science Foundation of Guangdong Province, China (grant no. 06104599).

\section{References}

1. Reya T, Morrison SJ, Clarke MF and Weissman IL: Stem cells, cancer, and cancer stem cells. Nature 1: 105-111, 2001.

2. Charafe-Jauffret E, Monville F, Ginestier C, Dontu G, Birnbaum D and Wicha MS: Cancer stem cells in breast: current opinion and future challenges. Pathobiology 75: 75-84, 2008.

3. Phillips TM, McBride $\mathrm{WH}$ and Pajonk F: The response of CD24(-/low) /CD44+ breast cancer-initiating cells to radiation. J Natl Cancer Inst 98: 1777-1785, 2006.

4. Fillmore CM and Kuperwasser C: Human breast cancer cell lines contain stem-like cells that self-renew, give rise to phenotypically diverse progeny and survive chemotherapy. Breast Cancer Res 10: R25, 2008.
5. Liu R, Varghese S and Rabkin SD: Oncolytic herpes simplex virus vector therapy of breast cancer in C3(1)/SV40 T-antigen transgenic mice. Cancer Res 65: 1532-1540, 2005.

6. Wang J, Hu P, Zeng M, Rabkin SD and Liu R: Oncolytic herpes simplex virus treatment of metastatic breast cancer. Int J Oncol 40: 757-763, 2012.

7. Todo T, Martuza RL, Rabkin SD and Johnson PA: Oncolytic herpes simplex virus vector with enhanced MHC class I presentation and tumor cell killing. Proc Natl Acad Sci USA 98: 6396-6401, 2001.

8. Ponti D, Costa A, Zaffaroni N, Pratesi G, Petrangolini G, Coradini D, Pilotti S, Pierotti MA and Daidone MG: Isolation and in vitro propagation of tumorigenic breast cancer cells with stem/progenitor cell properties. Cancer Res 65: 5506-5511, 2005.

9. Neve RM, Chin K, Fridlyand J, Yeh J, Baehner FL, Fevr T, Clark L, Bayani N, Coppe JP, Tong F, Speed T, Spellman PT, DeVries S, Lapuk A, Wang NJ, Kuo WL, Stilwell JL, Pinkel D, Albertson DG, Waldman FM, McCormick F, Dickson RB, Johnson MD, Lippman M, Ethier S, Gazdar A and Gray JW: A collection of breast cancer cell lines for the study of functionally distinct cancer subtypes. Cancer Cell 10: 515-527, 2006.

10. Wakimoto H, Kesari S, Farrell CJ, Curry WT Jr, Zaupa C, Aghi M, Kuroda T, Stemmer-Rachamimov A, Shah K, Liu TC, Jeyaretna DS, Debasitis J, Pruszak J, Martuza RL and Rabkin SD: Human glioblastoma-derived cancer stem cells: establishment of invasive glioma models and treatment with oncolytic herpes simplex virus vectors. Cancer Res 69: 3472-3481, 2009.

11. Hirsch HA, Iliopoulos D, Tsichlis PN and Struhl K: Metformin selectively targets cancer stem cells, and acts together with chemotherapy to block tumor growth and prolong remission. Cancer Res 69: 7507-7511, 2009.

12. Lim $\mathrm{E}$ and Winer EP: Adjuvant chemotherapy in luminal breast cancers. Breast (Suppl 3): 128-131, 2011.

13. Slamon DJ, Leyland-Jones B, Shak S, Fuchs H, Paton V, Bajamonde A, Fleming T, Eiermann W, Wolter J, Pegram M, Baselga J and Norton L: Use of chemotherapy plus a monoclonal antibody against HER 2 for metastatic breast cancer that overexpresses HER2. N Engl J Med 344: 783-792, 2001.

14. Romond EH, Perez EA, Bryant J, Suman VJ, Geyer CE Jr, Davidson NE, Tan-Chiu E, Martino S, Paik S, Kaufman PA, Swain SM, Pisansky TM, Fehrenbacher L, Kutteh LA, Vogel VG, Visscher DW, Yothers G, Jenkins RB, Brown AM, Dakhil SR, Mamounas EP, Lingle WL, Klein PM, Ingle JN and Wolmark N: Trastuzumab plus adjuvant chemotherapy for operable HER2positive breast cancer. N Engl J Med 353: 1673-1684, 2005.

15. Carey LA, Perou CM, Livasy CA, Dressler LG, Cowan D, Conway K, Karaca G, Troester MA, Tse CK, Edmiston S, Deming SL, Geradts J, Cheang MC, Nielsen TO, Moorman PG, Earp HS and Millikan RC: Race, breast cancer subtypes, and survival in the Carolina Breast Cancer Study. JAMA 295: 2492-2502, 2006.

16. Banerjee S, Reis-Filho JS, Ashley S, Steele D, Ashworth A, Lakhani SR and Smith IE: Basal-like breast carcinomas: clinical outcome and response to chemotherapy. J Clin Pathol 59: 729-735, 2006.

17. Fulford LG, Reis-Filho JS, Ryder K Jones C, Gillett CE, Hanby A, Easton D and Lakhani SR: Basal-like grade III invasive ductal carcinoma of the breast: patterns of metastasis and long-term survival. Breast Cancer Res 9: R4, 2007.

18. Al-Hajj M, Wicha MS, Benito-Hernandez A, Morrison SJ and Clarke MF: Prospective identification of tumorigenic breast cancer cells. Proc Natl Acad Sci USA 100: 3983-3988, 2003.

19. Ginestier C, Hur MH, Charafe-Jauffret E, Monville F, Dutcher J, Brown M, Jacquemier J, Viens P, Kleer CG, Liu S, Schott A, Hayes D, Birnbaum D, Wicha MS and Dontu G: ALDH1 is a marker of normal and malignant human mammary stem cells and a predictor of poor clinical outcome. Cell Stem Cell 1: 555-567, 2007.

20. Gonzalez-Angulo AM, Morales-Vasquez F and Hortobagyi GN: Overview of resistance to systemic therapy in patients with breast cancer. Adv Exp Med Biol 608: 1-22, 2007.

21. O'Brien CS, Farnie G, Howell SJ and Clarke RB: Breast cancer stem cells and their role in resistance to endocrine therapy. Horm Cancer 2: 91-103, 2011.

22. Ahtiainen L, Mirantes C, Jahkola T, Escutenaire S, Diaconu I, Osterlund P, Kanerva A, Cerullo V and Hemminki A: Defects in innate immunity render breast cancer initiating cells permissive to oncolytic adenovirus. PLoS One 5: e13859, 2010. 